\title{
Educação não formal no contexto brasileiro e internacional: tensões que perpassam a formulação conceitual
}

\author{
Non-formal education in the Brazilian and international scenario: tensions that permeate its \\ conceptual formulation
}

\author{
Renata Sieiro Fernandes* \\ Valéria Aroeira Garcia
}

\section{Resumo}

\begin{abstract}
Este artigo apresenta um estudo bibliográfico que visa apresentar o percurso histórico de constituição do campo da educação não formal nos contextos internacional e nacional, de modo a perceber como se deu a criação conceitual e teórica desse campo, bem como suas implicações. Dessa forma, a educação não formal tangencia as relações com a educação formal e apresenta algumas problemáticas advindas de suas origens e mudanças histórico-conceituais envolvendo os públicos atendidos por programas e projetos do terceiro setor, organizações de capital público, privado e misto, em ações realizadas fora da escola. $\mathrm{O}$ artigo traz subsídios para a fundamentação teórica e prática nesse campo conceitual e educacional. Conclui-se que o lugar atribuído ao campo da educação não formal orbita a periferia e as margens em relação à centralidade do campo da educação formal. Entender, conceitualmente, os dois campos como autônomos e independentes, que se interpenetram, com mobilidade e sem fronteiras definidas, talvez seja um caminho para a integração e valorização de muitas formas de se praticar educação, sem desmerecimentos e descréditos, possibilitando, inclusive, a diversidade de propostas educacionais.
\end{abstract}

Palavras-chave: Campo conceitual. Contexto histórico. Educação não formal. Revisão bibliográfica.

Recebido em 16/06/2018 - Aprovado em 30/10/2018

http://dx.doi.org/10.5335/rep.v26i2.7200

Doutora e pós-doutora em Educação pela Universidade Estadual de Campinas. Docente do Curso de Mestrado em Educação e do Curso de Pedagogia do Centro Universitário Salesiano de São Paulo, campus Americana, São Paulo, Brasil.E-mail: rsieirof@hotmail.com

** Doutora em Educação pela Universidade Estadual de Campinas. Pós-doutoranda em Educação na Universidade de São Paulo. Supervisora educacional na rede pública municipal de Campinas, São Paulo, Brasil. E-mail: va_garcia@ hotmail.com 


\section{Abstract}

The article is a bibliographical study that aims to present the historical course of constitution of the field of non formal education in the international and national contexts in order to perceive how the conceptual and theoretical creation of this field was giving itself as well as its implications. In this way, non-formal education touches relationships with formal education and presents some problems arising from its origins and historicalconceptual changes involving the public served by programs and projects of the third sector, public, private and mixed capital organizations in actions out of school. This article brings subsidies for the theoretical and practical foundation in this conceptual and educational field. It is concluded that the place attributed to the field of nonformal education orbits the periphery and the margins in relation to the centrality of the field of formal education. To understand, conceptually, the two fields as autonomous and independent, that interpenetrate, with mobility and without defined boundaries, is perhaps a way for the integration and valorisation of many forms of practicing education, without demerit and discredit, allowing even the diversity of educational proposals.

Keywords: Conceptual field. Historical context. Non-formal education. Literature review.

\section{Introdução}

Este artigo se caracteriza por um estudo bibliográfico e visa apresentar o percurso histórico de constituição do campo da educação não formal nos contextos internacional e nacional, de modo a perceber como se deu a criação conceitual e teórica desse campo ao longo do tempo, bem como suas implicações.

Pensar e falar em educação implica assumir um campo teórico e prático que, desde há muito tempo, mistura-se e confunde-se, mesmo não sendo sinônimo, com a terminologia e o território da escola. Entretanto, educação acontece também, e especialmente, onde não existe essa instituição responsável por promover o que se denomina como processo de ensino.

Ao se tratar da educação, entende-se formação ou percurso formativo, realizado por meio de práticas e processos educativos que implicam subjetivação, humanização e socialização, em que trocas, reconfigurações e manutenções de aspectos culturais e simbólicos acontecem nos grupos sociais, sem preocupações com formalizações, por meio de situações e experiências (em que o aprender está presente).

Educação e aprendizagem acontecem o tempo todo, em diferentes espaços e de várias formas. Para que se possam analisar e buscar compreender os vários e possíveis processos educacionais, didaticamente, denominam-se esses processos institucionalizados ou não pelos termos: educação formal, educação não formal e educação informal.

Rogers (2005, p. 68) usa a imagem do iceberg ao falar desses contextos educacionais, explicando que a parte visível, na superfície, é a que se refere à educação formal, a outra parte, ainda visível, mas mais próxima da água, mais abrangente 
que a parte anterior, é a que se refere à educação não formal, e a parte invisível, submersa, de maior amplitude e base para as partes anteriores, é a que se refere à educação informal. Portanto, todas estão conectadas, mas a educação formal adquire maior visibilidade e status, ao longo do tempo, realocando a educação não formal para a periferia. A educação informal é o que sustenta e perpassa todos os outros contextos, tamanha é sua força de atravessamento e sustentação. Dessa forma, a analogia do autor desenha o binômio centro-periferia como imagens que dialogam entre si, mas que tomam a educação formal como referência, e tudo o mais que não é escola, mas que engloba um leque amplo de experiências educativas, seja tratado como contraposição, como se fosse possível, inclusive, algo ser identificado por uma negação.

Busca-se fugir dessa imagem, dando autonomia e independência à educação não formal, assumindo-a como um campo conceitual não exatamente novo, mas, no caso do Brasil, em absorção recente pelo universo acadêmico e de pesquisa científica, constituído por reflexões e práticas que ocorrem em espaços de educação, de forma institucionalizada ou não, atendendo a diferentes públicos e em interface com diferentes áreas do conhecimento. Tais práticas e reflexões interdisciplinares podem ocorrer sob a forma de projetos e programas financiados tanto pelo poder público como por fundações públicas, privadas ou de capital misto, como também por empresas, associações, grupos comunitários, coletivos e movimentos.

É necessário apontar que as ações no campo da educação não formal não se destinam especificamente às classes populares. Ela acontece para diferentes públicos, de qualquer idade, e faz parte do percurso formativo das classes sociais de modos variados, por vezes, ao lado do percurso escolar (PALHARES, 2009). Dessa forma, o uso da terminologia "não formal" não procura uma configuração e constituição que designe um determinado lócus de acontecimento (que os termos "comunitário" e "social" possam indicar) e uma especificidade de público atendido (que o termo "social" ou "em vulnerabilidade" possa recortar), mas um campo sem fronteira e topografia definidas e estanques, com mobilidade e permeabilidade.

\section{0 contexto histórico da educação não formal}

O conceito de "não formal" ganha popularidade após a Segunda Guerra Mundial e o período de criação de novas nações independentes (BOCK; BOCK, 1985), pela necessidade de se incrementarem visões alternativas à escolarização formal 
como um meio de auxiliar a resolver, de maneira rápida e barata, problemas de desenvolvimento econômico e social.

Os anos 1960 são o marco do aparecimento e uso da terminologia e da nomenclatura indicadas por "non formal education". É nesse momento que elas aparecem, conceitualmente, em uma conferência de apresentação e discussão de problemáticas advindas do contexto escolar, a International Conference on World Crisis in Education, em 1967, em Williansburg, Virginia, nos Estados Unidos, evento patrocinado pela Organização das Nações Unidas para a Educação, a Ciência e a Cultura (UNESCO), em seu programa de educação. Esse momento marca a percepção e a assunção de existência da crise na educação em sua tarefa de educar a todos, em sua diversidade econômica e diferenciação sociocultural, bem como a crença na educação como alavanca de transformação e mudança social, auxiliando o desenvolvimento econômico (um pensamento datado historicamente com fortes conotações colonialistas). Nos países denominados, à época, de subdesenvolvidos ou em vias de desenvolvimento (ao que hoje se chamam de periferia do capitalismo internacional e financeirizado), as ações educacionais fora do campo da educação formal, que já aconteciam (especialmente em meio rural), ganham visibilidade, e, então, é cunhado e adotado o uso do termo educação não formal. Sendo assim, o início dos anos 1970 é marcado por uma grande empolgação com as possibilidades de ações formativas no campo da educação não formal (BOCK; BOCK, 1985).

O Instituto Internacional de Planejamento da UNESCO, sob a coordenação de Coombs, elabora um documento-base a partir dessa conferência, apontando a necessidade de se desenvolverem meios educativos que não se restringissem somente aos escolares, ainda que estivessem, fortemente, vinculados à ideia do ensino-aprendizagem. A obra é a versão revisada do texto original, de 1968, da obra de Coombs, The world educational crisis, em que o autor dedica um capítulo inteiro ao tema da educação não formal marcando sua importância e validade. Como desdobramento, nos anos 1970, um grupo de estudos da Universidade de Michigan, em colaboração com a Agência dos Estados Unidos para o Desenvolvimento Internacional (Usaid), organismo empenhado em fazer alinhamentos com as políticas dos EUA, propõe que ações realizadas por meio da "non formal education" possam alavancar a educação nos países subdesenvolvidos, valendo-se do discurso assumido de tentar realizar por outros modos as funções e tarefas que a escola não consegue ou deixa de fazer, entretanto, envolvendo menores recursos, investimentos e tempo. E, assim, dá-se apoio internacional a outras formas e meios de se praticar ações de educação menos custosas e que já aconteciam em países periféricos de 
forma espontânea (COOMBS, 1985), em consonância com as reformas econômicas impetradas pelos EUA e pela Inglaterra, na vertente neoliberal.

A partir da oficialidade e da publicidade dada ao conceito, a educação não formal como campo pertencente ao setor educacional começa a se configurar e a se circunscrever.

O programa de Michigan/Usaid, que em 1974 incorporou um centro de informação sobre educação não formal, desenvolveu um trabalho de elaboração de materiais didáticos e de metodologias no campo da educação não formal (PASTOR HOMS, 2001 apud GARCIA, 2015). Foram produzidos documentos avalizados pelas universidades e pelos organismos exteriores, bem como foi escrito, pelos acadêmicos Coombs, Prosser e Ahmed, um documento para o Fundo das Nações Unidas para a Infância (UNICEF), órgão das Nações Unidas, intitulado New paths to learning for rural children and youth (1973).

Coombs e Ahmed produzem duas publicações para o Banco Mundial, Attacking rural poverty: how non formal education can help (1974) e Education for rural development: case studies for planners (1975). La Belle e Verhine (1975) e La Belle (1986) editam um levantamento de programas latino-americanos no âmbito não escolar e, também, organizam um simpósio para apresentação e discussão de ideias, denominado Comparative Education Review, em 1976.

Logo, percebe-se a vinculação de ações realizadas no campo da educação não formal a um processo que pode ser vantajoso economicamente e apoiado por agências de desenvolvimento, como o Banco Mundial, a UNESCO e o UNICEF, ancorado por professores ligados ao universo acadêmico, o que conduz à busca por modelos bem sucedidos de experiências e à publicação de muitos estudos de casos.

Materiais e produções foram importantes meios da divulgação da terminologia e do conceito de educação não formal (em contraposição, competição e detrimento da educação formal), especialmente os documentos redigidos nas línguas inglesa, espanhola e francesa: Tesauro de la educación, da UNESCO, de 1977; Terminología de la educación de adultos, da UNESCO, de 1979; Documentation et information pedagogiques, de 1979; International review of education, de 1982; e Enciclopedia internacional de la educación, de 1989 (PASTOR HOMS, 2001); perpassando os anos de 1970-1980, reconhecidamente, o prenúncio da implementação de políticas de viés neoliberal.

Pelos materiais compilados, coletados e publicados, percebe-se a trajetória histórica e cronológica dos campos partindo da educação informal para a educação não formal, sendo a educação formal o último estágio a surgir (BOCK; BOCK, 
1985). Ainda, nota-se que a discussão sobre esses três campos aparece, primeiramente, nos Estados Unidos, depois passa para a Europa e só mais tarde chega ao Brasil. Essa trajetória da terminologia fica nítida pelos estudos realizados por Trilla (1999) e Pastor Homs (2001), na Espanha, e pelos verbetes constantes da International encyclopedia of education, nos Estados Unidos.

$\mathrm{Na}$ Espanha, na introdução e no estudo do conceito foram pioneiras as Jornadas de estudio sobre la educación informal, em 1974, organizadas pelo Departamento de Pedagogía Sistematica, da Universidad de Barcelona, portanto, avalizadas pela universidade e pelo instituto de Pedagogia (área de conhecimento aplicado da educação).

\section{Educação não formal no contexto brasileiro}

Como se afirmou anteriormente, as ações formativas desenvolvidas no campo da educação não formal já aconteciam desde antes de a terminologia ser cunhada. Os relatórios da UNESCO tratavam de experiências educacionais chamando-as, nos anos de 1950, de desenvolvimento comunitário, de educação comunitária, de educação rural e de educação no campo; no período de ditadura, nos anos de 1970, chamando-as de letramento funcional, de educação popular e de educação de jovens e adultos, até serem denominadas por educação não formal, ganhando notoriedade e destaque mesmo não sendo algo exatamente novo (RADCLIFFE; COLLETTA, 1985).

No mesmo período, no Brasil, também estava presente a discussão da crise da educação, entendida como crise da escola, uma vez que, para pesquisadores ligados à UNESCO, esta instituição não atendia às demandas sociais e culturais atribuídas a ela, especialmente relativas à diminuição do analfabetismo. Várias experiências em relação à alfabetização de jovens e adultos, muitas delas vinculadas à formação política, são exemplos marcantes e referenciais de experiências fora da escola desse período, como a educação popular e as campanhas de alfabetização apresentadas por Paulo Freire.

Dos anos 1980 até os anos 2000, há um período de experiências de escolarização em tempo integral, institucionalizadas, mantidas pelo Estado, voltadas para as crianças das classes populares, visando atender às necessidades e aos interesses desse grupo social. São exemplos: as escolas-parque (1950), na gestão de Anísio Teixeira; os parques infantis, na gestão de Mário de Andrade (1935); os Centros Integrados de Educação Pública (Ciep), na gestão de Darcy Ribeiro (1980); os Centros de Atenção Integral à Criança (Ciac), na gestão de Fernando Collor de Melo 
(1992); e os Centros Educacionais Unificados (CEU), na gestão de Marta Suplicy (2001). Nessas experiências, a proposta era oferecer uma educação voluntária, no contraturno da frequência escolar obrigatória.

Dos anos 1980 em diante, junto ao processo de democratização, advém uma forte crise econômica, que, concomitantemente à política neoliberal, estimula a organização civil e o terceiro setor, chamando-os a atuar no campo das políticas sociais e a buscar alternativas para as desigualdades socioeconômicas e educacionais de nosso tempo.

Esse período é chamado de boom das organizações do terceiro setor, que passam a se responsabilizar pelo desenvolvimento de ações educativas, muitas delas acontecendo no campo da educação não formal. A partir dos anos 1990, ainda seguindo a política neoliberal, o poder público passa a se desresponsabilizar de suas funções sociais, atribuindo ao terceiro setor e à sociedade civil algumas ações sociais, dentre elas as educativas, sendo que grande parte dessas ações passa a ocorrer no campo da educação não formal.

Percebe-se como o Estado brasileiro, em consonância com o projeto neoliberal, foi se desresponsabilizando de assumir para si a tarefa da educação das classes populares, tanto em ações e projetos no campo da educação formal (que se caracteriza pela ampliação do acesso, mas não de garantia da qualidade) como no campo da educação não formal, caracterizando-se pelo repasse de verbas ao terceiro setor por meio de programas, projetos e atendimento a editais. Assim, o Estado deixa de ser o órgão prestador, para ser a entidade contratante.

Fora do contexto brasileiro, as demandas e problemáticas no campo da educação não formal assumem particularidades e especificidades, embora em alguns pontos convirjam, especialmente por fazerem parte da agenda política e econômica neoliberal que atravessa países de todos os continentes.

\section{Educação não formal no contexto internacional}

Na Espanha, as discussões em torno da temática da educação não formal iniciam-se na década de 1970, sendo já citadas as Jornadas de estudio sobre la educacion informal, organizadas pelo Departamento de Pedagogia Sistemática da Universidad de Barcelona, ocorridas em 1974 (PASTOR HOMS, 2001). Sendo que, na década de 1980, dá-se a entrada definitiva do conceito de educação não formal nos discursos oficiais. 
Ao lado disso, a Assembleia Parlamentar do Conselho da Europa adota, em 2000, a recomendação sobre educação não formal,

[...] incitando todos aqueles que dão forma às políticas educativas a tomar conhecimento da educação não formal como parte essencial do processo educativo [...] e interpelando os governos e outras autoridades competentes dos Estados-Membros a reconhecer a educação não formal como um parceiro de fato no processo de aprendizagem ao longo da vida. ${ }^{1}$

A recomendação feita aos Estados pertencentes à Convenção Cultural Europeia (2003) é para reafirmar que o campo da educação não formal constitui uma dimensão fundamental no processo de aprendizagem ao longo da vida e que se deve trabalhar para o desenvolvimento de padrões de reconhecimento efetivo das ações no campo da educação não formal como parte essencial da educação em geral.

Dessa forma, a educação não formal se coaduna a buscas de novas adaptações formativas para os mercados que se transformam:

O "conceito novo" de educação ao longo da vida é revelador de um fenômeno societário que o pesquisador em ciências da educação John Field (2000, p. 133) chamou de "nova ordem educativa". Aprender ganha um significado novo para a sociedade inteira, para as instituições educativas e para os indivíduos. Essa reconfiguração não deixa de ter uma contradição interna: a nova aprendizagem primeiramente inscreve-se em um quadro econômico e político cujos objetivos são a competitividade, a empregabilidade e a adaptabilidade das "forças de trabalho" (ALHEIT; DAUSIEN, 2006, p. 178).

\section{A Comissão Europeia e a UNESCO reconhecem que,}

[...] no contexto do princípio da aprendizagem ao longo da vida, a identificação e a validação da aprendizagem não formal e informal têm por finalidade tornar visível e valorizar todo o leque de conhecimento e competências detidos por uma pessoa, independentemente do local ou da forma como foram adquiridos. A identificação e a validação da aprendizagem não formal e informal têm lugar dentro e fora do ensino e formação formais, no local de trabalho e na sociedade civil (PINTO, 2005, p. 1).

Vários países europeus têm ações e dão credibilidade e aval para o campo da educação não formal, assumindo-o em seus documentos legais e oferecendo formação aos educadores em âmbito universitário por meio de curso técnico ou de graduação em educação social e pedagogia social, constituindo o território profissionalizante e o público de atendimento.

De acordo com a bibliografia estudada, é possível compreender como o campo da educação não formal vem se constituindo em diferentes países e por onde se estrutura, sendo que muitas das práticas têm relações com o social (entendido como populações ou grupos sociais em vulnerabilidade ou com baixo poder aquisitivo e localizado em comunidades). 
Os Estados Unidos, particularmente, têm papel importante, sendo o primeiro país a cunhar o termo educação não formal e a formular as bases teóricas a partir de levantamento de experiências práticas que já aconteciam em países periféricos - como já foi descrito anteriormente -, contribuindo para a sistematização e a produção bibliográfica que circulou e circula por outros países. Ao lado disso, enfrentam problemáticas sociais advindas do contexto multicultural que lhes é próprio, por meio de ondas de imigração, criando necessidade de experiências também fora do ambiente escolar, como as ações práticas de homeschooling (educação doméstica) e de nonschooling ou unschooling - inspiradas em Illich, em Sociedade sem escolas (1979), e em outros autores libertários, cuja opção das famílias é pela não escolarização ou desescolarização.

Na década de 1970, os estudos realizados por Brembeck, no Program of studies in non-formal education, do Institute for International Studies in Education (IISE), e as pesquisas da Universidade de Michigan sinalizaram a importância de pesquisas no campo da educação não formal (BREMBECK, 1976, p. 12).

O Programa de Estudos da Universidade de Michigan, coordenado por Brembeck, traz as preocupações específicas do momento histórico, da posição econômica e política dos Estados Unidos e de seus interesses em relação aos países denominados em desenvolvimento e aos investimentos direcionados à elevação dos níveis de escolaridade e enfrentamento do analfabetismo. Isso reforça o papel reservado ao campo da educação não formal dentro de uma visão desenvolvimentista e economicista, mas também colonialista, na relação centro-periferia dos países imperialistas.

Fica claro o interesse econômico e desenvolvimentista, quando se notam que as práticas no campo da educação não formal se davam em situações de pobreza e/ ou com poucos recursos, nas quais, muitas vezes, destacavam-se como alternativas de educação mais barata, mais rápida e com amplitude para se atingir um público maior.

Na Europa, na Finlândia, práticas realizadas no campo da educação não formal se relacionam com a área da educação social, que teve sua origem no Serviço e na Assistência Social.

Na Irlanda, país caracterizado pelo Estado de Bem-Estar Social, a problemática que acomete o país é a vulnerabilidade dos velhos em períodos de solidão e as altas taxas de suicídio de jovens, temáticas abordadas por diferentes projetos no campo da educação não formal (RYYNÄNEN, 2009).

A educação infantil nos países nórdicos também se insere no campo da educação não formal, embora, como faz parte do sistema educativo, é cunhada por 
não escolar. São exemplos disso os programas de pré-escola de período parcial e integral, as cooperativas de pais, as creches domiciliares e os centros recreativos, os programas de pré-escola aberta desenvolvidos na Suécia e a pré-escola do bosque, na Dinamarca. (HAMMERSHØJ, 1996 apud HADDAD, 1996; HADDAD; JOHANSSON, 1995). Os programas, as ações e as propostas que acontecem no campo da educação não formal são coordenados pelo Ministério/Secretaria de Bem-Estar Social, e os que são realizados pela educação formal são coordenados pelo Ministério/Secretaria de Educação.

Ao considerar as práticas no campo da educação não formal realizadas no continente africano, a produção bibliográfica apresenta obras especialmente dos anos 1950 e 1960, sendo algumas delas com público adulto: Planning non-formal education in Tanzania; L'education des adultes au Sénegal: classrooms in the factories, classrooms in the military, literacy: three pilot projects; La formation profissionelle des adultes em notes et etudes documentaries.

Sheffield e Diejomaoh (1972) também retratam a educação não formal na África, enquanto Van Rensburg (1974) apresenta o seu trabalho pioneiro em Botswana. Em algumas situações, as propostas no campo da educação não formal foram apontadas como necessárias para desenvolver e realizar ações educativas específicas em comunidades rurais. Dahama e Bhatnagar (1985) apontam uma série de características referentes às vantagens que se podem obter ao utilizar práticas da educação não formal em relação à educação no campo e para aqueles que não tiveram ou que tiveram acesso restrito ao sistema formal de ensino. Para os autores, além da educação formal e não formal, há a extensão em educação, que combina a educação de adultos com os campos da educação informal e não formal e tem seu foco de interesse em adultos não alfabetizados (principalmente agricultores e trabalhadores braçais), sendo a intenção alfabetizá-los não somente na gramática, mas em melhores técnicas naquilo que mais lhes interessar.

$\mathrm{Na}$ Índia, a educação formal foi tratada como incapaz de dar conta de todas as necessidades educacionais do país e a educação não formal passou a estar presente, inclusive, por recomendação do Comitê Central de Aceleração da Educação.

No Japão, o campo da educação não formal, também chamado de educação social, foi utilizado como instrumento de educação nacionalista e, após 1945, houve uma mudança de rumo, sendo a ênfase dada à reorientação do povo, visando à formação de bons cidadãos em uma sociedade democrática (MORO’OKA, 1985).

Em 1929, o Japão funda o Escritório de Educação Social, no Ministério Educacional, para lidar com assuntos referentes aos jovens e aos grupos de crianças, 
oferecendo centros de treinamento de juventude, escolas de complementação vocacional, biblioteca, museus, educação de adultos, grupos de educação social, autorização e recomendação de livros como formação continuada e permanente. No ano de 1995, estabelece-se a Direção da Educação Não Formal, para coordenar ações do governo e das iniciativas privadas, de modo a garantir a efetivação da educação básica entre crianças e adultos, colocando ambas em relação (educação não formal e educação formal).

No Uruguai, muitas das práticas que acontecem no campo da educação não formal são denominadas de Educação Social. No XVI Congresso Mundial dos Educadores Sociais, em 2005, foi redigido um documento-referência, marco conceitual das competências do educador social, que se destinaria a ser a referência a partir da qual se realizariam os debates e o desenvolvimento da base profissional dos educadores sociais nas ações socioeducativas em meios fechados e abertos.

As problemáticas abordadas no trabalho socioeducativo dizem respeito a crianças, adolescentes e adultos com deficiência, assim como aqueles com um fator de risco concreto: pessoas com transtorno mental, dependentes do álcool ou de outras drogas, indigentes, pessoas em conflito com a lei, em diferentes situações de vulnerabilidade, etc.

Em Cuba, o programa intitulado "Educa a tu hijo", do Ministerio de Educación, (CUBA, 1992), é oferecido para aqueles que estão fora do sistema educacional formal e foca tanto as crianças quanto os adultos responsáveis pelo cuidado delas, em sua maioria avôs, avós, cuidadores e mães grávidas.

Embora os exemplos sejam breves, por esse leque de experiências fora do Brasil, possíveis de serem encontradas em publicações e na internet, percebem-se as diferentes vertentes de ação no campo da educação não formal e como se diferenciam pelo contexto social e pelo período histórico.

Em algumas situações e propostas, credita-se ao campo da educação não formal o potencial para atingir alguns dos objetivos que a educação formal tem falhado em obter, ou seja, aquela é vista com a capacidade única para preencher algumas funções que são atribuídas à escolarização formal e para, além disso, visando complementá-la, suplementá-la ou sendo alternativa a esta. E disso deriva o risco de surgirem discursos que polarizam os campos: educação não formal versus educação formal, em termos de qualidade e necessidade. Entretanto, as críticas apontam que várias iniciativas realizadas no campo da educação não formal não têm conseguido promover mudanças sociais, sem uma intencionalidade prévia, podendo servir a concepções e propostas tanto transformadoras como reformadoras ou mantenedo- 
ras do status quo, dependendo da orientação político-filosófica da instituição em relação ao seu projeto societário e de formação de sujeitos e de grupos sociais.

As possíveis rivalidades e contraposições entre os campos podem ser notadas a partir da construção conceitual do campo da educação não formal ao longo dos espaços-tempos apontados por Garcia (2015) e pela afirmativa de sua potência como campo de experimentação e resistência a práticas hegemônicas e de enfrentamento do neoliberalismo.

\section{A construção do campo teórico-conceitual}

As construções conceituais apresentadas cronologicamente servem para mostrar o movimento na criação de conceitos, particularidades, persistências e recriações ao longo dos espaços-tempos.

Conforme apontado, a terminologia educação não formal é cunhada por Philip Coombs, na década de 1960. Para o autor, a educação não formal se configura pelo desenvolvimento de meios educativos que não se restringem somente aos escolares.

Pastor Homs (2001) encontra na obra de Coombs, Prosser e Ahmed (1973) a primeira preocupação em diferenciar e definir os termos. Trilla (1996) confirma que o termo educação não formal tornou-se popular no contexto educacional em 1967, na International conference on world crisis in education, em Williamsburg, Virginia, Estados Unidos, apontando a necessidade de desenvolver meios educativos que não se restringissem somente aos escolares.

Keis, Lang, Mietus e Tiapula (1976 apud BREMBECK, 1976) estabelecem distinções conceituais nos campos educacionais, incluindo a educação incidental. Para eles, a educação incidental caracteriza-se por experiências educacionais não intencionais, mas não menos poderosas em seus efeitos e ressonâncias. Os resultados são produzidos sem consciência ou intenção e são, comumente, pensados como sendo "naturais" ou "inerentes", mas eles são, de fato, fruto de processos de aprendizagem.

Diferentemente da educação incidental, a informal refere-se às mesmas experiências ou a similares que podem ser, conscientemente, examinadas e, deliberadamente, incrementadas, por meio de conversa, explanação, interpretação, instrução, disciplina e imitação do exemplo de outros; ocorrendo pela vivência individual e social do dia a dia, pela via da socialização.

Ainda nos anos 1970, Brembeck (1976), coordenador do Grupo de Estudos em Educação Não Formal, da Universidade de Michigan, sistematizou alguns pontos 
basilares dos campos da educação formal e da educação não formal, apontando seus contrários, por meio de um exercício de comparação entre eles.

Os pontos considerados são os seguintes:

a) estrutura: os programas da educação formal são estruturados em um sistema coordenado e sequencial; os programas da educação não formal costumam ter muito menos centralização e estrutura comum;

b) conteúdo: a educação formal geralmente é acadêmica, teórica e verbal, enquanto que a educação não formal é, normalmente, centrada em tarefas ou habilidades, com objetivos que se relacionam com a aplicação prática em situações diárias;

c) tempo: a educação formal é orientada para o tempo futuro; a educação não formal é de curto prazo e orientada para o tempo presente;

d) gratificação: na educação formal, os "retornos" tendem a ser adiados e são de longo alcance, enquanto na educação não formal, os "retornos" tendem a ser tangíveis e imediatos ou em curto prazo;

e) local: a educação formal tem visibilidade e localidade, enquanto a educação não formal, usualmente, tem baixa visibilidade e pode ocorrer em quase todos os lugares;

f) método: a educação formal transmite conhecimentos padronizados, do professor para o estudante na sala de aula, enquanto a educação não formal tende a ter mais conteúdos específicos, com esforços instrucionais dirigidos à aplicação prática;

g) participantes: os aprendizes da educação formal são separados por idade e os professores são formalmente certificados; os aprendizes da educação não formal podem ser de todos os grupos etários e os educadores têm uma grande variedade de qualificação ou não são, necessariamente, certificados formalmente; em termos de aprovação social, os estudantes que "falham" na educação formal podem sofrer estigma social; já os participantes da educação não formal podem "falhar" com pequeno ou nenhum estigma social;

h) função: as experiências em educação formal, geralmente, são designadas para ir ao encontro das supostas necessidades que as pessoas têm; a educação não formal, mais frequentemente, é designada em resposta às necessidades que as pessoas dizem ter. 
Afonso (1989, p. 78), no final da década de 1980, em Portugal, motivado pelo seu envolvimento com os movimentos sociais no Brasil e o associativismo, no momento de democratização, bem como pela repercussão da educação popular e pelo reconhecimento das ações educacionais de Paulo Freire, propõe definir os termos da seguinte forma:

[...] por educação formal, entende-se o tipo de educação organizada com uma determinada sequência e proporcionada pelas escolas, enquanto que a designação informal abrange todas as possibilidades educativas no decurso da vida do indivíduo, constituindo um processo permanente e não organizado. A educação não formal, embora obedeça também a uma estrutura e a uma organização (distintas, porém das escolas) e possa levar a uma certificação (mesmo que não seja essa a finalidade) diverge ainda da educação formal no que respeita a não fixação de tempos e locais e à flexibilidade na adaptação dos conteúdos de aprendizagem a cada grupo concreto.

Embora, no campo da educação não formal, exista uma formalidade, o autor aponta para uma possível ausência de normatização, abrindo espaço no instituído para que possam acontecer experiências instituintes. Para ele, antes de tudo, as ações no campo da educação não formal devem levar a uma transformação social, com viés assumidamente político.

São elencadas algumas características que devem ser constitutivas desse campo educacional, tomando como embasamento as organizações e os movimentos sociais e populares: a) apresentar caráter voluntário; b) promover a socialização; c) promover a solidariedade; d) visar ao desenvolvimento; e) preocupar-se essencialmente com a mudança social; f) ser pouco formalizados e pouco hierárquicos; g) favorecer a participação; h) proporcionar investigações e projetos de desenvolvimento; i) ser, por natureza, formas de participação descentralizadas.

Afonso (1989), por vezes, usa o termo não escolar como sinônimo de não formal e propõe que seja a sociologia da educação não escolar a área de conhecimento responsável pelo estudo teórico e prático das problemáticas advindas desse campo.

Gohn (1999) apresenta a educação não formal, primeiramente, ligada aos movimentos sociais e ao associativismo, até, recentemente, incluir um leque mais ampliado que engloba as práticas das organizações do terceiro setor: aprendizagem política dos direitos; educação para o trabalho; práticas com objetivos comunitários; desenvolvimento da leitura do mundo; a educação na e pela mídia; etc.

Trilla (1996), que participa desde o início das criações conceituais sobre educação não formal na Espanha, ocupou-se de compreender a trajetória e o escopo das terminologias utilizadas, considerando, para tanto, as questões administrativas e legais definidas pelo organismo responsável no país por legislar e deliberar sobre 
a educação. Sendo assim, a partir da compreensão do autor, podem-se definir os termos como: a educação informal é a aprendizagem que realizamos na função de aprendizes e de ensinantes, em que não há planejamento e intencionalidade, que ocorre sem que nos apercebamos, como acontece, por exemplo, na educação familiar; a educação formal é intencional, possui uma forma determinada por uma legislação nacional, tem critérios específicos para acontecer e segue o que é estipulado pelo Estado; a educação não formal é aquela mediada pela relação de ensino-aprendizagem, com intencionalidade e forma, assumindo e desenvolvendo metodologias com procedimentos e ações diferenciadas das adotadas nos sistemas formais, e, no caso brasileiro, não tem uma legislação nacional que a regule e que incida sobre ela.

Brennan (1997), da Universidade de New England, propõe três tipos de aplicação da educação não formal, claramente, relacionados à educação formal, colocando-a em desvantagem: a) educação não formal como um complemento ao sistema formal; b) educação não formal como um suplemento ao sistema formal; e c) educação não formal como uma alternativa à educação formal.

Nos anos 2000, Garcia (2015), no Brasil, ao se debruçar sobre a conceituação dos campos, tomando a filosofia deleuziana como organizadora do pensamento e das reflexões, propõe que sejam entendidos como campos conceituais e territoriais distintos, não havendo necessidade de um ser definido em função do outro. A autora aposta na ideia de campos autônomos e independentes conceitualmente; dessa forma, eles conversam, complementam-se, alimentam-se e constituem uns aos outros, mas com identidades próprias.

Sob essa óptica, a cada campo se reservam suas funções, em estado de (re) invenção, garantindo espaço para convivências frutíferas e enriquecedoras, propiciando que os sujeitos e os grupos sociais possam ser beneficiados nesses processos constantes e diários de formação ao longo da vida ou permanentemente, por meio da diversidade de fazeres e pensares, existindo, nessas relações, disputas, entrechoques, recriações conceituais, realimentação de um pelo outro.

Também, por essa óptica, não se alimenta o discurso de negar a educação formal em favor de investimentos em propostas e experiências, em programas e projetos realizados no campo da educação não formal:

A recente valorização do campo da educação não formal pode significar ou implicar a desvalorização da educação escolar. Por essa razão, a justificação da Educação Não Escolar não pode ser construída contra a escola, nem servir a quaisquer estratégias de destruição dos sistemas políticos de ensino, como parecem pretender alguns dos arautos da ideologia neoliberal (AFONSO, 2001, p. 31). 
Esse é um dos riscos a ser evitado e um cuidado a ser tomado.

\section{Considerações finais}

Ao abordar o campo da educação não formal, alguns pontos podem e devem ser levados em conta em sua contextualização, conceituação e caracterização. Dentre eles, pode-se mencionar o lugar atribuído ao campo da educação não formal, observado em muitas concepções orbitando a periferia e as margens em relação à centralidade do campo da educação formal.

A proposta de se entender conceitualmente os dois campos como autônomos e independentes, que se interpenetram, relacionam-se, tangenciam-se, com mobilidade e sem fronteiras definidas, talvez seja um caminho para a integração e valorização de muitas formas de se praticar educação, sem desmerecimentos e descréditos, possibilitando, inclusive, a diversidade de propostas educacionais.

É preciso atentar para os discursos que permeiam muitas das propostas no campo da educação não formal, afirmando intenções e ações que visam à transformação social, mas que acabam por responder com ações reformistas e de manutenção da situação vigente, sendo o projeto político da instituição a diretriz de sua proposta educacional e de sociedade. A isso se associa o fato de ainda se estar sob a égide do modelo neoliberal, tanto no Brasil quanto no mundo.

A revalorização do campo da educação não formal, a partir dos anos 1990, assim como a justificação de propostas nesse campo não podem ser construídas contra a escola, nem servir a discursos e estratégias de destruição dos sistemas públicos de ensino, como defende a ideologia neoliberal, implicando na desvalorização da educação escolar, especialmente a pública.

A sistematização por parte dos educadores de seus pensares e fazeres é bastante importante para as trocas e a estruturação das produções no campo da educação não formal, de modo que eles próprios sejam também produtores e divulgadores de conhecimento, já que as ações pedagógicas nesse campo estão muito calcadas na oralidade, fragmentadas e sem registros reflexivos e sistematizados que realimentem as práticas e a reflexão sobre ela (FERNANDES, 2007).

É preciso investimento em pesquisas nesse campo da educação, de modo que haja uma produção teórica nacional de qualidade e que seja referência, desenvolvendo embasamento teórico e prático, dialogando com as produções internacionais e com as práticas realizadas. 
As pesquisas nesse campo ainda são incipientes tanto de tipo qualitativo como qualitativo-quantitativo, talvez como reflexo de uma tímida absorção das práticas no campo da educação não formal como campo de pesquisa e ensino nas universidades, que em geral objetivam a formação dos estudantes para o campo da educação formal, bem como validação de estágio. Ainda que não se pleiteie uma formação específica para o campo da educação não formal, em nível técnico e universitário, apesar de isso já acontecer na Europa e em alguns lugares da América Latina (ao analisar o recorte da educação social), não se pode negar sua existência, tampouco o campo de trabalho de muitos profissionais da pedagogia e de outras áreas.

No início de janeiro de 2013, foi publicada, no Diário Oficial da União, a Portaria no 4, que institui a Escola Nacional de Socioeducação (ENS), no âmbito da Secretaria de Direitos Humanos da Presidência da República (SDH/PR), com o objetivo de promover a qualificação e a profissionalização dos cerca de 20 mil agentes públicos que atuam na rede de atendimento aos jovens em conflito com a lei no Brasil. É a primeira iniciativa visando à formação profissional desses educadores em nível nacional, fora de contexto formal e escolar. As primeiras turmas dos cursos serão na modalidade de educação a distância e oferecidas a partir de convênio com a Universidade de Brasília, em parceria com universidades estaduais e municipais.

A construção do campo da educação não formal ora disputa e ora compartilha lugares conceituais e territoriais também pleiteados pela educação social - juntamente com a pedagogia social - e pela educação sociocomunitária, o que amplia, diversifica e prolifera as discussões e os debates, sendo algo rico e produtivo.

Há que se mencionar o envolvimento e as lutas dos movimentos sociais de militância das associações estaduais, nacionais e internacionais de educadores sociais pela criação e regularização da profissão de educador e educadora social, já constante na Classificação Brasileira de Ocupações, desde 2009, uma conquista recente para a configuração desse profissional que já atua na atenção, defesa e proteção a pessoas em situação de risco e vulnerabilidade social, bem como na preservação e conquista de direitos.

A formação no campo da educação formal para profissionais atuarem no campo da educação social está em discussão na Câmara dos Deputados, por meio do Projeto de Lei $n^{\circ} 5.346 / 2009$, de autoria do deputado Chico Lopes (PCdoB). A formação por meio de cursos nos níveis técnico e universitário envolve um amplo debate, e há necessidade de amplificá-lo para além das questões técnicas, administrativas e estruturais de uma "nova" formação, que se faz necessária por sua prática que já 
acontece há tempos, em diferentes contextos, nos campos político, social e cultural brasileiros.

A questão que merece destaque é que essa discussão não pode acontecer sem considerar as diferentes "formações" já existentes e que vêm acontecendo por ações realizadas no campo da educação não formal, debatendo e produzindo saberes e práticas para os acontecimentos cotidianos que se fazem por meio da educação social. Portanto, a estruturação da formação, em níveis técnico e universitário, para os educadores sociais é importante e necessário em nosso país, mas é fundamental que essa organização se dê em articulação e diálogo com os movimentos sociais e com os educadores sociais que vêm atuando, construindo e criando esse fazer e esse campo educacional/social no Brasil.

\section{Nota}

1 Disponível em: <http://www.wakeseed.org/conteudos.php?id=64\&m=1>. Acesso em: 16 jun. 2018.

\section{Referências}

AFONSO, Almerindo J. Os lugares da educação. In: SIMSON, O. R. de M.; PARK, M. B.; FERNANDES, R. S.(Org.). Educação não formal: cenários da criação. Campinas, SP: Editora da Unicamp; Centro de Memória, 2001. p. 79-93.

Sociologia da educação não-formal: reactualizar um objecto ou construir uma nova problemática? In: ESTEVES, Antonio Joaquim; STOER, Stephen R. A sociologia na escola. Porto: Afrontamento, 1989. p. 83-96.

ALHEIT, Peter; DAUSIEN, Bettina. Processo de formação e aprendizagens ao longo da vida. Educação e Pesquisa, São Paulo, v. 32, n. 1, p. 177-197, abr. 2006.

BOCK, John C.; BOCK, Christoph M. Nonformal education: policy in developing countries. In: HUSEN, Torsten; POSTLETHWAITE, Neville (Ed.). The international encyclopedia of education: research and studies. New York: Pergamon Press Ltd., 1985. v. 6. p. 3551-3556.

BRASIL. Portaria nº 4, de janeiro de 2013. Institui a Escola Nacional de Socioeducação no âmbito da Secretaria de Recursos Humanos da presidência da República, e estabelece diretrizes para o seu funcionamento. Diário Oficial da União, 12 jan. 2015.

BREMBECK, Cole S. Introducción. In: BREMBECK, Cole S.; THOMPSON, Timothy J. (Org.). Nuevas estrategias para el desarrollo educativo: investigación intercultural de alternativas no formales. Buenos Aires: Editorial Guadalupe, 1976. p. 9-16.

BRENNAN, Barrie. Reconceptualizing non-formal education. Internacional Journal of Lifelong Education, EUA, v. 16, n. 3, p. 185-200, May/June 1997. 
COOMBS, Philip. Non formal education: comparative studies. In: HUSEN, Torsten; POSTLETHWAITE, Neville (Ed.). The international encyclopedia of education: research and studies. New York: Pergamon Press Ltd., 1985. v. 6. p. 3536-3540.

COOMBS, Philip; AHMED, Manzoor. Attacking rural poverty: how non formal education can help. New York: UNICEF; International Center for Educational Development, 1974.

COOMBS, Philip; AHMED, Manzoor. Education for rural development: case studies for planners. New York: Praeger, 1975.

COOMBS, Philip; PROSSER, Roy; AHMED, Manzoor. New paths to learning for rural children and youth. New York: UNICEF; International Center for Educational Development, 1973.

DAHAMA, Omprkash P.; BHATNAGAR, Omprkash P. Education and communication for development. 2. ed. Calcutá: Oxford/IBH Publishing Co., 1985.

FERNANDES, Renata Sieiro. Os educadores na educação não formal: apontamentos e reflexões. Revista de Ciências da Educação, Americana, SP: Unisal, ano IX, n. 17, p. 67-94, 2º sem. 2007.

GARCIA, Valéria A. Educação não formal como acontecimento. Holambra: Setembro, 2015.

GOHN, Maria da G. Educação não formal e cultura política: impactos sobre o associativismo do terceiro setor. São Paulo: Cortez, 1999.

HADDAD, Lenira. Políticas integradas de cuidado e educação infantil: o exemplo da Escandinávia. Revista Pro-Posições, Campinas, v. 7, n. 3 [21], p. 36-50, nov. 1996.

HADDAD, Lenira; JOHANSSON, Jan-Erik. A pré-escola sueca: a história de um sistema integrado de cuidado e educação. Cadernos Cedes, Campinas, n. 37, p. 45-61, 1995.

ILLICH, Ivan. Sociedade sem escolas. Petrópolis: Vozes, 1979.

LA BELLE, Thomas J. Nonformal education in Latin America and the Caribbean: stability, reform, or revolution? New York: Praeger, 1986.

LA BELLE, Thomas J.; VERHINE, Robert E. Education, social change, and social stratification. In: LA BELLLE, Thomas J. (Org.). Educational alternatives in Latin America. Los Angeles: UCLA Latin American Center Publications, 1975. p. 132-135.

CUBA. Ministerio de Educación. Educa a tu hijo. Cuba: Editorial Pueblo y Educación, 1992.

MORO'OKA, Kazufusa. Nonformal education in Japan. In: HUSEN, Torsten; POSTLETHWAITE, Neville (Ed.). The international encyclopedia of education: research and studies. New York: Pergamon Press Ltd., 1985. v. 6. p. 3536-3558.

PALHARES, José Augusto. Reflexões sobre o não escolar na escola e para além dela. Revista Portuguesa de Educação, Braga: Universidade do Minho, v. 22, n. 2, p. 53-84, 2009.

PASTOR HOMS, Maria Inmaculada. Orígenes y evolución del concepto de educación no formal. Revista Española de Pedagogia, Madrid, año LIX, n. 220, p. 525-544, sep./dic. 2001.

PINTO, Luis Castanheira. Sobre educação não formal. Cadernos d'InEducar, 2005. Disponível em: <http://docplayer.com.br/97859-Em-2003-o-comite-de-ministros-do-conselho-da-europa-recomenda-aos-estados-pertencentes-a-convencao-cultural-europeia.html>. Acesso em: 20 out. 2018. 
RADCLIFFE, David J.; COLLETTA, Nat J. Nonformal education. In: HUSEN, Torsten; POSTLETHWAITE, Neville (Ed.). The international encyclopedia of education: research and studies. New York: Pergamon Press Ltd., 1985. p. 1837-1842.

RYYNÄNEN, Sanna. A Pedagogia Social na Finlândia e o contexto brasileiro. In: SOUZA NETO, João Clemente de; SILVA, Roberto da; MOURA, Rogério Adolfo (Org.). Pedagogia social. São Paulo: Expressão e Arte, 2009. Disponível em: <https://socialeducation.files.wordpress.com/2010/11/ caliman-pedagogia-social-italia.pdf>. Acesso em: 20 out. 2018.

ROGERS, Alan. Non-formal education: flexible schooling or participatory education? New York: The University of Hong Kong HFR Kluwer Academic Publishers, 2005.

SHEFFIELD, James R.; DIEJOMAOH, Victor P. Non-formal education in African development. New York: African-American Institute, 1972.

VAN RENSBURG, P. Report of Swaneng Hill: education and employment in African country. Uppsala: Day Hammerskjold Foundation, 1974.

TRILLA, Jaume. A educación non formal e a cidade educadora. Dúas perspectivas (unha analítica e outra globalizadora) do universo da educación. Revista Galega do Ensino, La Coruña, n. 24, p. 199-221, set. 1999.

La educación fuera de la escuela: ámbitos no formales y educación social. Barcelona: Ariel, 1996. 